\title{
ACESSO À EDUCAÇÃO PELA INTERNET: POLÍTICAS PÚBLICAS PARA GARANTIA DOS DIREITOS FUNDAMENTAIS
}

\section{Leandro Carvalho dos Santos Silva ${ }^{1}$ Fernando Antônio de Vasconcelos ${ }^{2}$}

RESUMO: O direito à educação e o acesso à internet são considerados hoje como direitos fundamentais. Torna-se necessário o desenvolvimento de esforços que envolvam governo e sociedade no sentido de facilitar o acesso à educação, contribuindo para a consolidação desses direitos. Objetiva analisar as políticas públicas de educação à distância como garantia de direitos fundamentais. Busca discorrer sobre educação não presencial no Brasil, apresentando uma visão sobre o formalismo das políticas educacionais e perspectivas de uma educação jurídica à distância. Utiliza pesquisa exploratória e bibliográfica. Por fim, examina políticas públicas de inclusão do ensino jurídico à distância para igualdade de oportunidades.

PALAVRAS-CHAVE: Educação à distância; Ensino Jurídico; Políticas públicas; Igualdade de oportunidade; Novas Tendências Pedagógicas.

\section{ACCESS TO EDUCATION OVER THE INTERNET: PUBLIC POLICIES TO GUARANTEE FUNDAMENTAL RIGHTS}

ABSTRACT: The right to education and access to the Internet are now considered as fundamental rights. It becomes necessary to develop efforts involving government and society in the sense of access to education, contributing to the consolidation of the law. It aims to analyse as public policies of distance education as a guarantee of fundamental rights. Seeks to talk about non-face-to-face education in Brazil, presenting an insight into the formalism of educational policies and perspectives of a distance legal education. Using exploratory and bibliographic research. Finally, examines public policies for the inclusion of legal education at a distance for equal opportunities.

KEYWORDS: Distance education; Legal education; Public policy; Equality opportunity; New pedagogical tendencies.

\section{INTRODUÇÃO}

A internet é uma ferramenta de inter-relacionamento, que proporciona grandes conquistas e inúmeros benefícios, trazendo, também, aspectos que possibilitam a socialização do conhecimento. Um fator de grande influência nasce com a possibilidade de sua utilização

\footnotetext{
1 Mestrando em Direito e Desenvolvimento pelo Programa de Pós-Graduação em Direito do Centro Universitário de João Pessoa - PPGD/UNIPÊ. Advogado. E-mail: carvalhossadv@ gmail.com

${ }^{2}$ Doutor e Mestre em Direito Civil pela UFPE. Professor do Programa de Pós-Graduação em Direito do Centro Universitário de João Pessoa - PPGD/UNIPÊ e do Programa de Pós-Graduação em Ciências Jurídicas da Universidade Federal da Paraíba - PPGCJ/UFPB. E-mail: fer.mengo@uol.com.br.
} 
como forma de acesso da educação à distância, surgindo com o objetivo de promover oportunidades para massificação do acesso ao conhecimento. Seu maior objetivo está relacionado ao atendimento de grandes contingentes de alunos, de forma mais efetiva, para promoção da igualdade de oportunidades e a consequente realização de um direito de acesso à educação, como meio de efetivação da dignidade da pessoa humana.

A educação à distância (EAD) no Brasil tem evoluído de forma a atender uma grande demanda de público que não estão inseridos nas garantias constitucionais, por exclusão do acesso à educação. Nesta senda, permite a interação e a cooperação entre pessoas distantes geograficamente ou inseridas em contextos diferenciados, de modo que se apresenta como protagonista na concretização de igualdade de oportunidade na realização de justiça social.

No âmbito do ensino jurídico, tem-se percebido um crescente interesse no que se refere à educação à distância nas modalidades profissionalizantes de aperfeiçoamento e na modalidade latu sensu. No entanto, o rigor e o formalismo da educação jurídica ainda se constituem uma barreira para a oferta da EAD, na modalidade stricto sensu.

Nesse sentido, no presente trabalho procuraremos realizar uma rápida análise sobre as políticas públicas de educação à distância para garantia de direitos fundamentais, buscando discorrer sobre a educação à distância no Brasil e procurando mostrar uma visão sobre o formalismo da educação jurídica e as perspectivas de uma educação jurídica condizente com os dias atuais.

Como metodologia adota-se pesquisa exploratória e bibliográfica. Exploratória por constituir uma primeira etapa de uma investigação mais ampla, que tem como principal finalidade desenvolver, esclarecer e modificar ideias (GIL, 2006, p. 43). E, bibliográfica, por consistir basicamente em selecionar informações bibliográficas como livros, dicionários, artigos, artigos científicos e documentos que possam contribuir para explicar o problema objeto da investigação. (HENRIQUES; MEDEIROS, 2017, p. 106).

Ao final, busca-se examinar as referidas políticas públicas de inclusão do ensino jurídico à distância considerado à luz da Constituição Federal, na tentativa de inserir a EAD no contexto da consolidação dos direitos fundamentais, reconhecendo esse acesso como uma garantia de igualdade de oportunidades na efetivação de direitos fundamentais.

Assim sendo, esta pesquisa se encontra em consonância com o conteúdo previsto no Grupo de Trabalho "Cultura Jurídica e Educação Constitucional”, uma vez que atende ao seu objetivo, pela realização de uma abordagem que abrange novas tendências pedagógicas para a educação em direitos fundamentais e direitos humanos. Isto porque a EAD permite a 
igualdade de oportunidade como garantia do direito ao acesso à educação, como meio de efetivação da promoção da dignidade da pessoa humana.

\section{TEORIA DA JUSTIÇA DISTRIBUTIVA E PRINCÍPIO DA IGUALDADE DE OPORTUNIDADES}

A ideia de justiça parte do pressuposto de que esta deve ser compreendida como julgamento ético sobre a correlação em determinado momento entre entidades sociais, referente ao valor da sua situação para cada uma destas, e principalmente, quando tais correlações decorrem dos bens da sociedade. (KOLM, 2000).

Na Constituição Federal de 1988, verificou-se, no âmbito da proteção específica aos direitos fundamentais do cidadão, uma preocupação adicional com o direito à educação. Podese dizer que esses direitos são estudados e observados juntamente com os postulados básicos da cidadania, constituindo verdadeiro pressuposto e fundamento dos direitos humanos. Não há como se falar em direito à educação quando a estrutura da sociedade se distancia da democracia, estando esta, também indicada por muitos filósofos como o sustentáculo da cidadania e da promoção da dignidade da pessoa humana.

A deficiência do acesso ao direito à educação suprime direitos fundamentais, externando a problemática da carência de igualdade de oportunidade, refletindo na ausência de promoção da educação como fator de desenvolvimento sociocultural.

Nessa conjuntura, sob a perspectiva de uma justiça distributiva, quando Kolm (2000, p. 38), explica que as entidades sociais, devem ser compreendidas como justiciáveis, esclarece que “[...] quanto 'mais' para um justiciável implicar 'menos' pra outro, o problema da justiça será de justiça distributiva", no sentido de que, uma justiça que se considera respeitável arbitra entre os desejos antagônicos dessas entidades. O referido autor apresenta um conjunto de variáveis que refletem diretamente na avaliação ética, destacando-se para esta pesquisa, a variável de relevância ética direta, ao estabelecer os valores finais ético-sociais para a justiça.

Kolm (2000), esclarece que uma justiça respeitável trata de agentes justiciáveis e por esse motivo, tem como alicerce uma teoria da ação. Isto é, agentes podem praticar ações dotadas de vontade, que por sua vez, está dotada de intenções, e estas podem influenciar atos desses agentes. Desta forma, Kolm (2000, p. 47), esclarece que:

[...] o direito de um agente pode ser visto como uma liberdade socialmente definida em um sentido amplo do termo, uma vez que implica, direta ou indiretamente, a possibilidade de escolha por parte desse agente. [...] O objetivo de um agente pode 
ser tanto um 'objetivo final' quanto um 'objetivo intermediário' desse agente, que influencia seus objetivos finais - por exemplo, como um meio de praticar novas ações. Exemplos de objetivos finais dos indivíduos são a felicidade, a satisfação das necessidades finais, a 'auto realização', a possibilidade de ter uma 'vida boa', de levar uma vida moral, etc.,

Nesse quadro, a justiça distributiva tem como um dos princípios mais importantes nos debates políticos o princípio da igualdade de oportunidades. Segundo Kolm (2000, p. 294), “[...] a ideia é que todas as pessoas devem receber chances iguais na vida, que elas usarão segundo seus desejos, força de vontade e outras capacidades". O referido autor adverte sobre a necessidade de traçar uma fronteira entre os elementos que não estão equalizados nem compensados, e esclarece que a consideração de injustiça está na desigualdade nos meios de atividade econômica de que a sociedade provê os indivíduos, colocando a questão da falta de oportunidade para a educação ou os resultados da educação como foco dessas injustiças.

Assim, Kolm (2000, p. 294), esclarece que:

O que se considera injusto é a desigualdade nos meios de atividade econômica (em particular, a competição) de que a sociedade provê os indivíduos. Portanto, o foco está na discriminação, na educação (oportunidade para a educação ou resultado da educação), na herança e, secundariamente, nas relações sociais e nas diversas informações.

Outrossim, ainda segundo o referido autor, a igualdade de oportunidade também pode ser usada como igualdade de liberdade ou de meio, opondo-se a ideia de igualdade de resultado, por meio do conceito de responsabilidade. Seguido esse entendimento, a incorporação plena da responsabilidade na teoria da justiça distributiva, tem sua moral baseada na noção de responsabilidade de atendimento das necessidades de outrem, assim como, a dignidade da pessoa humana, na necessidade dessa responsabilidade, podendo ser tratado no âmbito do senso de justiça e estando acentuada no sentimento de injustiça das pessoas.

Na mesma linha de raciocínio, Amartya Sen (2010), ao tratar das liberdades instrumentais - o modo como diferentes tipos de direitos, oportunidades e intitulamentos contribuem para a expansão da liberdade humana em geral, evidencia a oportunidade social, na forma de serviços de educação como instrumento de facilitação da participação econômica, como meio de ajudar a gerar a abundância individual, além de recursos públicos para os serviços sociais. Ainda segundo o referido autor, as políticas públicas visando ao aumento das capacidades humanas e das liberdades substantivas em geral podem funcionar por meio da promoção dessas liberdades distintas, mas inter-relacionadas. (SEN, 2010, p. 25). 
Diante desse quadro, torna-se perceptível a compreensão de que a consecução de uma justiça distributiva em que se possa efetivar a igualdade de oportunidade, perpassa pelo alcance de liberdade como meio e fim para atingir o desenvolvimento humano e consequentemente a promoção da dignidade da pessoa humana, de modo que essa liberdade só pode ser alcançada por meio de políticas públicas que visem a democratização do acesso à educação e a informação.

\section{A EDUCAÇÃO À DISTÂNCIA NO BRASIL}

A Educação à Distância, ao longo de sua história, traçou uma trajetória de avanços e retrocessos. No início do século XX, tornou-se uma modalidade de ensino capaz de atender a todos os níveis, incluindo programas formais de ensino, ou seja: aqueles que oferecem diplomas ou certificados e programas de caráter não formais, que tem como objetivo oferecer capacitação para a potencialização e melhoria das atividades profissionais.

A Constituição Federal de 1988 aborda o direito à educação, de forma expressa, em seu art. $6^{\circ}$, inserindo-o como sedo um direito fundamental social, exigindo-se a participação efetiva do Estado para sua concretização. (BRASIL, 1988).

Nesse contexto, insere-se a educação a distância como um fator de inclusão social. Existem diversos conceitos de Educação a Distância, sempre com muitos pontos em comum. Todavia, destaca-se conceito do Decreto 9.057/17, que em seu artigo $1^{\circ}$ assevera que:

\footnotetext{
Para os fins deste Decreto, considera-se educação a distância a modalidade educacional na qual a mediação didático-pedagógica nos processos de ensino e aprendizagem ocorra com a utilização de meios e tecnologias de informação e comunicação, com pessoal qualificado, com políticas de acesso, com acompanhamento e avaliação compatíveis, entre outros, e desenvolva atividades educativas por estudantes e profissionais da educação que estejam em lugares e tempos diversos. (BRASIL, 2017, online)
}

Na mesma perspectiva, Moran (2009) esclarece que na modalidade de educação à distância, professores e alunos estão separados fisicamente no espaço e/ou no tempo, podendo não apresentar momentos presenciais, por ser realizada através do intenso uso de tecnologias de informação e comunicação.

Fazer com que o ensino superior esteja ao alcance de todas as pessoas que desejem estudar torna-se uma forma de oportunizar o acesso educação, proporcionando igualdade de condições independentemente da distância ou posição geográfica do cidadão. Segundo dados do Instituto Nacional de Estudos e Pesquisas Educacionais Anísio Teixeira-INEP, as CONPEDI LAW REVIEW | QUITO - EQUADOR | v. 4 | n. 2 | p. 96 - 110 | JUL - DEZ | 2018 
instituições não só começam a ampliar a oferta de cursos superiores de graduação e pósgraduação nessa modalidade, como já oferecem, exclusivamente, cursos à distância, sem a oferta simultânea de cursos presenciais. Atualmente, mais de 1,3 milhão de estudantes estão matriculados em cursos EAD em todo o país. (INEP, 2016, online)

A oferta da modalidade de cursos à distância no Brasil recebeu autorização legal para o seu devido funcionamento, de forma exclusiva em cursos de graduação e pós-graduação lato sensu, ambos na modalidade à distância. Essa medida tem por objetivo incentivar a disseminação desses cursos em todo o território nacional, buscando-se sempre o desenvolvimento sociocultural e o acesso à educação e informação de qualidade.

O número de instituições públicas e privadas de ensino, que oferecem cursos nesta modalidade, tem crescido significativamente no Brasil depois da publicação da Lei de diretrizes e Bases - LDB em 1996. Segundo dados do INEP, o Brasil tem 2.070 cursos de ensino a distância em 317 instituições, o que representa um aumento significativo comparando-se com o período de entrada em vigor da legislação que estabelece as diretrizes e bases da educação nacional. (INEP, 2016, online). Segundo Tomelin (2016, p. 21), com base nos dados da Associação Brasileira de Educação à Distância - ABED, em relação à evolução da educação à distância das instituições ao longo dos últimos anos no Brasil, a maioria das instituições que responderam ao censo,

[...] dos últimos sete anos está localizada no Sudeste do Brasil, com uma média de 42\% de representação. Observamos uma queda, em 2013, para 40\% e, em 2016, para $37 \%$. Segundo o censo do INEP de 2015, a região Sudeste concentra $42 \%$ das instituições que ofertam EAD.

Já na região Sul, a média histórica é de $23 \%$, e em 2016 houve um crescimento importante na participação, passando aos 27\%. Segundo o censo do INEP de 2015, a região Sul abriga $24 \%$ das instituições.

No Centro-Oeste, a média é de 13\%, com uma representação menor em 2016, de $11 \%$. Já para o INEP, a região tem $7 \%$ de participação.

A região Norte, que em 2010 representava 3\%, em 2016 passou para 7\%, ficando muito perto do reportado pelo INEP, que é de $6 \%$.

O Nordeste também teve um leve crescimento nos últimos dois anos, passando de uma média de $16 \%$ para $18 \%$. Para o INEP, o Nordeste concentra $21 \%$ das instituições.

O artigo 80 da LDB estabelece que "o poder público incentivará o desenvolvimento e a veiculação de programas de ensino a distância, em todos os níveis e modalidades de ensino e de educação continuada" (BRASIL, 1996, online).

Apesar do progresso recente da educação a distância, muitos pontos precisam ser discutidos para sua plena efetivação. Destacam-se como pontos ainda controversos, os seus objetivos, forma de transmissão, acesso regional, métodos de avaliação, expansão para pós- 
graduação stricto sensu na área jurídica, entre outros. Ainda é necessária uma expansão de suas competências, uma maior distribuição regional e igualitária, que proporcionem o acesso irrestrito da população que procure os serviços educacionais à distância.

Os avanços tecnológicos tornaram mais visíveis as possibilidades de desenvolvimento da EAD, podendo proporcionar um acesso irrestrito a educação por parte da população que busca o acesso ao ensino á distância. Países como Suécia, Inglaterra, França, bem como, Canadá e EUA e mais recentemente o Brasil, são considerados grandes propulsores da metodologia da educação à distância.

O Ministério da Educação tem dedicado atenção a esta modalidade de ensino e vem publicando uma série de portarias normativas que estão servindo de fonte legal para demarcar os espaços, as formas de atuação das instituições e as características dos cursos.

Segundo a ABED (2017, p.73), a maioria dos cursos à distância “[...] são especializações lato sensu, com uma oferta de 1.098 cursos. Com uma grande distância, também há 235 ofertas de cursos em nível tecnológico, 219 em nível técnico profissionalizante e 210 ofertas de licenciaturas".

Ainda segundo a ABED (2017, p. 73), onde se encontra ofertas menos frequentes “[...] estão na área da pós-graduação stricto sensu (mestrado e doutorado), com um total de 25 cursos, em comparação com 7 em 2015. No doutorado, 2016 foi o ano em que se registraram os primeiros 3 cursos em EAD".

Conforme especificado no Gráfico 1, os cursos da modalidade de Pós-graduação stricto sensu (doutorado), já o mestrado é em mais difundido com relação aos anos de 2015-2016, representam um índice menor com relação a ouras modalidades. Esses dados atestam que é preciso um maior investimento por parte do poder público e privado nesta modalidade educacional. Nesse cenário, no gráfico 1, apresenta-se o crescimento da oferta de cursos da educação básica à pós-graduação stricto sensu:

Gráfico 1 - Oferta de cursos no Brasil da modalidade à distância

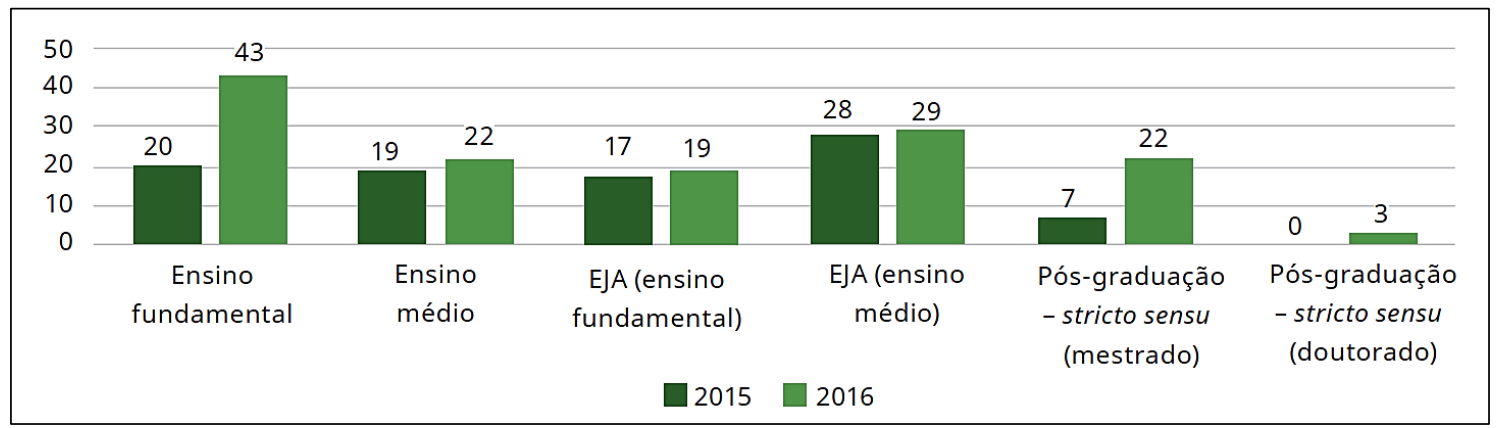

FONTE: Associação Brasileira de Educação à Distância - ABED (2017). 
Torna-se preciso expandir o número de instituições que o oferecem a modalidade de ensino stricto sensu, aproximando a população do conhecimento e oportunizando o acesso irrestrito a todas as modalidades e educação e conhecimento.

\section{A PERSPECTIVAS DE UMA EDUCAÇÃO JURÍDICA À DISTÂNCIA}

A educação jurídica tem passado por intensas discussões em âmbito curricular em razão das transformações advindas com as tecnologias de informação e comunicação, no sentido de transpor seu conservadorismo e se adequar à novas tendências pedagógicas que permitam seu ajustamento, principalmente a utilização da modalidade EAD. Segundo Brandão (2015, p. 207),

\footnotetext{
Não é difícil observar que a atuação dos profissionais da área jurídica ainda é extremamente conservadora. Portanto, faz-se necessária uma mudança na postura desses profissionais e na estrutura dos respectivos órgãos, no sentido de se implementar uma mudança social capaz de transformar a sociedade e não apenas de manter o que nela existe. Nesse sentido, a mudança deve começar no ensino do direito, tendo em vista que as propostas pedagógicas definidas por diretrizes curriculares demonstram esse conservadorismo.
}

O curso de Direito é pioneiro no ensino superior nacional, com um currículo predeterminado no período entre 1827-1951 (fixo e rígido), composto por nove cadeiras e com duração de cinco anos (RODRIGUES, 2005, p. 61).

Destaque-se, que só em 1962, o Conselho Federal de Educação criou e pela primeira vez, um currículo com bases mínimas para o ensino do Direito no Brasil, permitindo a construção de currículo plenos parcialmente diferenciados nas diversas instituições de ensino e sua adaptação às necessidades e realidades regionais. (RODRIGUES, 2005, p. 64-65).

Entretanto, no que pese as mudanças curriculares, contata-se que, muito se debate no Brasil com relação à qualidade e quantidade de cursos de Direito no mercado educacional brasileiro, pois a situação atual aproxima-se mais de um modelo tradicional do que um modelo inovador. O EAD em cursos jurídicos diminui distâncias e proporciona o acesso à informação e educação superior.

Isso faz com que a educação jurídica à distância seja tema central e alvo de constantes debates, elevando críticas e preocupando todos os protagonistas da carreira jurídica envolvidos com a pedagogia e sistema de ensino do Direito. Segundo dados do INEP (2016), 
a maioria das instituições de ensino a distância está localizada no Sudeste do Brasil, com uma média de $42 \%$ de representação.

Notadamente, as tecnologias existentes também estão inseridas nas dependências das universidades, e os sistemas de ensino, em geral, também devem dispor da modalidade à distância como alterativa de ampliação do aceso ao ensino jurídico. Além disto, os cursos jurídicos também para fugir do método tradicional (aula expositiva e presencial), devem fomentar o ensino jurídico à distância as modalidades stricto sensu para ampliar os campos e pesquisa em Direito, bem como propagar a pesquisa jurídica e dogmática nos diversas regiões e espaços geográficos.

Todavia, as pessoas que residem em cidades menores, ou em locais distantes ou de difícil acesso, devem ter efetivo acesso à uma educação stricto sensu de qualidade. Mas para fazê-lo, de modo a frequentarem cursos de pós-graduação tradicionais, precisam vencer distâncias, obstáculos e o formalismo exacerbado, notadamente esses fatores contribuem para o crescimento da oferta de cursos stricto sensu na modalidade à distância, embora esse crescimento ainda seja tímido.

E esse desafio faz-se mais árduo na EAD, em cursos de pós-graduação, visando romper o modelo metodológico padrão do professor expondo, em uma posição de hierarquia e o aluno que apenas observa a aula, muitas vezes sem um protagonismo educacional. Instigar o aluno a pensar, criticar e resolver problemas é um desafio constante para o ensino jurídico à distância.

Torna-se preciso que se quebrem paradigmas, a exemplo de: investimento na formação de um novo professor/educador, hábil a usar as novas tecnologias disponíveis no EAD; conscientizar o aluno da necessidade da pesquisa e motivá-lo a continuar com os estudos, pois segundo pesquisa realizada pela ABED os cursos de pós-graduação stricto sensu (mestrado e doutorado) à distância representam uma porcentagem mínima as pesquisas apresentadas.

\section{NOVAS TENDÊNCIAS PEDAGÓgICAS E POLÍTICAS PÚBLICAS}

Ao tratar-se de novas tendências pedagógicas educacionais, enfatizam-se as tendências que envolvem as modalidades de ensino que visam facilitar a sua democratização, cujo espectro está centrado na ideia do "aprender-fazendo" e, consequentemente, na realização de direitos fundamentais e promoção da dignidade da pessoa humana. 
Os avanços proporcionados pelo uso das tecnologias da informação e comunicação possibilitaram uma melhoria, tanto nas condições sociopolíticos e culturais, como na reformulação das bases pedagógicas e metodológicas ao promover transformações importantes nas formas tradicionais de ensino-aprendizagem. Nesse contexto, Bernardes e Rover (2010, p. 32) esclarece que:

Com efeito, a velocidade com que as TICs se desenvolveram alcançou inclusive os meios educacionais, gerando uma nova onda educacional que passa pela reformulação total da sua base pedagógica, metodológica, tecnológica, científica e institucional, a metodologia mais apropriada é a do learning doing (aprender fazendo). E a mais recente aliada dessa revolução educacional ostenta natureza tecnológica: consiste na combinação do ensino à distância (via satélite) como virtual (via internet) $[\ldots]$.

A educação à distância se aproxima de uma tendência progressiva que parte de uma análise crítica das relações sociais, cujo sustentáculo está ligado às finalidades sociopolíticas. Desta forma, segundo Marques (2010, p. 200), o campo do direito se depara com a necessidade de aperfeiçoamento em sua forma de ensino, tendo em vista que, as formas tradicionais vêm sendo suplantada e substituída por formas interativas e que exigem um maior comprometimento do aluno. Com base nessas necessidades, o ensino jurídico no Brasil, tem buscado integrar disciplinas em suas matrizes curriculares que envolvem a relação da tecnologia com o direito, como as disciplinas de informática jurídica ou aplicada ao direito, em face do uso das mesmas no ambiente profissional, como ocorre no caso do processo judicial eletrônico.

Além disso, a crescente oferta dos cursos de aperfeiçoamento e pós-graduação stricto sensu tem avançado no país cada vez mais, em virtude de uma grande demanda que envolve a necessidade de adequação de tempo-espaço e acesso democrático da Pós-graduação às exigências de qualificação para ingresso no mercado de trabalho, fazendo do EAD um instrumento de inclusão e promoção da dignidade da pessoa humana.

O Estado tem buscado acelerar o processo de inclusão por meio da educação à distância e, em particular, no âmbito da pós-graduação jurídica, na facilitação de acesso a essa modalidade de cursos, por meio de políticas públicas. Por políticas públicas, segundo Norat e Vasconcelos (2018), entende-se como sendo a união de atividades estatais que envolve atos e normas, caracterizando-se como um programa de ação do Governo com o intuito de efetivar a promoção de direitos sociais, econômicos e culturais.

Desse modo, o Decreto $\mathrm{n}^{\circ}$ 9.057, de 25 de maio de 2017, que regulamenta o artigo 80 da Lei $n^{\circ}$ 9.394, de 20 de dezembro de 1996, que estabelece as diretrizes e bases da educação nacional, amplia as possibilidades da oferta da educação à distância no país, ao permitir em 
seu artigo 11, a possibilidade de instituições privadas solicitarem credenciamento para a oferta de cursos superiores na modalidade à distância ao Ministério da educação. $\mathrm{O} \S 2^{\circ}$ do referido artigo, também inclui a possibilidade da oferta de pós-graduação lato sensu na modalidade à distância. (BRASIL, 2017, online).

No âmbito da pós-graduação lato sensu, o referido decreto também estabelece em sem seu artigo $11, \S 4^{\circ}$, a possibilidade das “[...] escolas de governo do sistema federal credenciadas pelo Ministério da Educação para oferta de cursos de pós-graduação lato sensu poderão ofertar seus cursos nas modalidades presencial e a distância. " (BRASIL, 2017, online). No mesmo sentido, no $§ 5^{\circ}$, determina que “[...] as escolas de governo dos sistemas estaduais e distrital deverão solicitar credenciamento ao Ministério da Educação para oferta de cursos de pós-graduação lato sensu na modalidade à distância”. (BRASIL, 2017, online)

Outrossim, a maior ênfase pode ser dada ao se observar o artigo 18, ao abrir possibilidade de oferta de pós-graduação na modalidade stricto sensu à distância. O referido artigo determina que, “[...] a oferta de programas de pós-graduação stricto sensu na modalidade a distância ficará condicionada à recomendação da Coordenação de Aperfeiçoamento de Pessoal de Nível Superior - Capes, observadas as diretrizes e os pareceres do Conselho Nacional de Educação”. (BRASIL, 2017, online).

Nesse diapasão, percebe-se uma abertura no âmbito da pós-graduação no Brasil para a oferta dos cursos de mestrado e doutorado na modalidade à distância, o que permitirá uma equalização na oferta dos cursos, para que as instituições de ensino possam ofertar a referida modalidade, como uma parcela considerável de graduados possa realizar o curso do local onde estiverem.

De relevante importância, pode-se destacar também a Lei no 13.632, de 6 de março de 2018, que altera a lei $n^{\circ}$ 9.394, de 20 de dezembro de 1996 (Lei de Diretrizes e Bases da Educação Nacional), para dispor sobre educação e aprendizagem ao longo da vida, em que inclui o inciso XIII do artigo $3^{\circ}$ da LDB, ao estabelecer que, o ensino será ministrado com base no princípio da garantia do direito à educação e à aprendizagem ao longo da vida (BRASIL, 2018).

Diante do exposto, percebe-se que essa preocupação anda em conformidade com promoção da dignidade da pessoa humana e democratização da educação por meio do acesso à educação. Fica clara a ampliação da possibilidade de acesso à educação e, em particular, na modalidade à distância, inclusive para os cursos de pós-graduação na área jurídica, uma vez que ainda se encontra restrito a uma parcela que ainda pode realizar presencialmente. Essa 
abertura permite a democratização do ensino de pós-graduação na área jurídica, e a consequente realização de igualdade de oportunidade para os que sofrem limitações de acesso.

\section{CONCLUSÕES}

Os índices de crescimento da educação à distância no Brasil têm sido consideráveis nos últimos anos, tendo em vista os avanços das tecnologias da informação e comunicação. Entretanto, o acesso à educação jurídica à distância ainda tem sofrido limitação em face do formalismo jurídico e na tradição das ofertas dos cursos jurídicos em todo o país.

As desigualdades de oferta em cursos presenciais, tanto por instituições públicas como privadas são perceptíveis, ao verificar que os cursos de pós-graduação jurídica se encontram concentrados nas regiões sul sudeste do país. Essas características refletem na necessidade de equalização do acesso à educação à distância pela igualdade de oportunidade.

Assim, a presente pesquisa apresentou a teoria da justiça distributiva partindo-se de uma visão principiológica da igualdade de oportunidades como fundamento para promoção da dignidade da pessoa humana por meio do acesso à educação. A importância de uma igualdade de oportunidade reflete em necessidades que envolvem desde a oportunidade de uso da internet, perpassa pelo acesso à educação e se estende até a elaboração de políticas públicas relevantes para o desenvolvimento social e cultural, e garantia dos direitos fundamentais.

Dessa forma, o Brasil por ter uma notável diversidade regional, criativa e cultural, necessita enfrentar seu problema mais urgente - a desigualdade social. Para isso se faz necessário fomentar, principalmente, políticas públicas de acesso à educação e inclusão digital, através da qual será facilitado o acesso à informação e às variadas formas de acesso à cultura. O fortalecimento de políticas públicas já se torna realidade no país, entretanto, faz-se necessário a integração com outras políticas, estimulando-se a criação e estruturação de órgãos em âmbito regional e estadual destinados a fomentar o acesso à educação, especialmente a que se acessa pela internet. Quando se amplia o acesso à cultura e ao conhecimento, respeitam-se os direitos fundamentais do cidadão inseridos na Carta Magna.

Nos últimos anos, o Estado tem elaborado políticas públicas, por meio de leis específicas, buscando ampliar o acesso à educação, e em particular ao acesso aos programas de pós-graduação na modalidade lato sensu e em especial a modalidade stricto sensu.

O uso das tecnologias de informação e comunicação tem facilitado esse processo possibilitando o desenvolvimento de atividades educativas que possam ser realizadas por meio da mediação entre professores/orientadores e alunos que se encontrem em lugares e em 
tempos distintos. A educação à distância tem melhorado tanto nas condições sociopolíticos e culturais como tem permitido a reformulação das bases pedagógicas e metodológicas cujo espectro está centrado na ideia do "aprender-fazendo".

Faz-se necessário o desafio da oferta de curso de pós-graduação EAD, visando romper o modelo metodológico padrão do professor expondo conteúdos, em uma posição hierárquica e o aluno que apenas observa a aula, devendo instigar o aluno a pensar, criticar e resolver problemas é um desafio constante para o ensino jurídico à distância.

Torna-se preciso romper o paradigma posto na educação presencial, e ter como ponto de partida o investimento na formação de um novo modelo de professor/educador, o qual possa desenvolver habilidades para o uso das novas tecnologias disponíveis no EAD; conscientizar o aluno sobre o "aprender-fazendo" e da necessidade da pesquisa, buscando motivá-lo a continuar com os estudos, uma vez que os cursos de pós-graduação stricto sensu (mestrado e doutorado) à distância representam ainda uma porcentagem mínima dos referidos cursos já existentes.

No âmbito da educação jurídica à distância, esta última modalidade de oferta surge como instrumento importante, no sentido de incentivar a igualdade de oportunidade para a democratização do acesso à educação. Todavia, se faz necessário que as políticas públicas também atuem no sentido de garantir uma boa qualidade dessas ofertas, para que os cursos oferecidos possam ser efetivos nas garantias fundamentais e que possam gerar desenvolvimento para o país.

Diante do que foi discutido, torna-se também relevante destacar que esta pesquisa não se propôs a uma discussão pronta e acabada, mas apenas a promover discussões no sentido de apresentar a teoria da justiça distributiva, como uma vertente de análise que desenvolve a visão do acesso à educação à distância para o desenvolvimento de políticas públicas, criadas efetivamente a partir do princípio da igualdade de oportunidade como meio de exercer a democratização da educação e promoção da dignidade da pessoa humana.

\section{REFERÊNCIAS}

ABED. Censo EAD.BR: Relatório Analítico da Aprendizagem à Distância no Brasil. Curitiba: InterSaberes, 2017. Disponível em: $<$ http://abed.org.br/censoead2016/Censo_EAD_2016_portugues.pdf>. Acesso em: 25 jun. 2018.

BERNARDES, Marciele Berger; ROVER, Aires José. Uso das novas tecnologias de informação e comunicação como ferramentas de modernização do ensino jurídico. 
Disponível em:

$<$ http://www.buscalegis.ccj.ufsc.br/revistas/index.php/observatoriodoegov/article/viewFile/33 640/32738>. Acesso em: 25 jun. 2018.

BRANDÃO, Fernanda Holanda de Vasconcelos. Desjudicialização dos Conflitos: necessidade de mudança de paradigma na educação jurídica. In: SANCHES, Samyra Haydêe Dal Farra Naspolini; MEZZAROBA, Orides; BIRNFELD, Carlos André Hüning. (Coords.). Direito Educação e Metodologias do Conhecimento. Florianópolis: CONPEDI, 2015. Disponível em: <https://www.conpedi.org.br/publicacoes/c178h0tg/017e0bex/89a86me6p0Mz3PZP.pdf>. Acesso em: 26 jun. 2018.

BRASIL. Constituição (1988). Constituição da República Federativa do Brasil. Brasília, DF: Senado Federal: Centro Gráfico, 1988. Disponível em: $<$ http://www.planalto.gov.br/ccivil_03/constituicao/constituicao.htm>. Acesso em: 26 jun. 2018.

BRASIL. Decreto n' 9. 057, de 25 de maio de 2017. Regula o artigo 80 da lei $\mathrm{n}^{\circ}$ 9.394, de 20 de dezembro de 1996, que estabelece as diretrizes e bases da educação nacional. Publicado no Diário Oficial da união em 26 de mio de 2017. Disponível em:

<http://www.planalto.gov.br/ccivil 03/ ato2015-2018/2017/decreto/D9057.htm>. Acesso em 25 jun. 2018.

BRASIL. Lei no 9.394, de dezembro de 1996. Estabelece as Diretrizes e Bases da Educação Nacional. Publicado no Diário Oficial da União em 23 de dezembro de 1996. Disponível em: <http://www.planalto.gov.br/ccivil 03/LEIS/L9394.htm>. Acesso em: 25 jun. 2018.

BRASIL. Lei $\mathbf{n}^{\mathbf{0}}$ 13.632, de 6 de março de 2018. Altera a Lei no 9.394, de 20 de dezembro de 1996 (Lei de Diretrizes e Bases da Educação Nacional), para dispor sobre educação e aprendizagem ao longo da vida. Publicado no Diário Oficial da União em 7 de março de 2018. Disponível em: <http://www.planalto.gov.br/ccivil_03/_ato2015-

2018/2018/lei/L13632.htm>. Acesso em: 25 jun. 2018.

GIL, Antônio Carlos. Pesquisa Social. 5. ed. São Paulo: Atlas, 2006.

HENRIQUES, Antônio; MEDEIROS, João Bosco. Metodologia Científica na Pesquisa Jurídica. 9. ed. São Paulo: Atlas, 2017.

INSTITUTO NACIONAL DE ESTUDOS E PESQUISAS EDUCACIONAIS ANÍSIO TEIXEIRA. Sinopse Estatística da Educação Superior 2016. Brasília: Inep, 2017. Disponível em: 〈http://portal.inep.gov.br/web/guest/sinopses-estatisticas-da-educacao-superior>. Acesso em: 25 jun. 2018.

KOLM, Serge-Christophe. Teorias Modernas de Justiça. São Paulo: Martins Fontes, 2000.

MARQUES, Carlos Alexandre Michaello. O Ensino Jurídico e as Novas Tecnologias de Informação e Comunicação. Revista de Educação , v. 13, n. 16, 2010, p. 199-214. Disponível em: 〈http://www.egov.ufsc.br/portal/sites/default/files/1849-7098-1-pb_0.pdf>. Acesso em: 25 jun. 2018. 
MORAN, José Manuel. Mudar a forma de ensinar e de aprender com tecnologias. Disponível em: <http://www.fluxos.com/aulas/TEXTOSIMGS/COMUNICACAO/Moran MUDAR_FORMA_D E_ENSINAR.pdf >. Acesso em: 25 jun. 2018.

NORAT. Markus Samuel Leite; VASCONCELOS. Fernando Antônio de. Direito do Consumidor e Educação pela Internet. João Pessoa: Markus Samuel Leite Norat. 2018.

RODRIGUES, Horácio Wanderlei. Pensando o Ensino do Direito do Direito no Século XXI. Florianopólis: Fundação Boiteux, 2005.

SEN, Amartya. A Ideia de Justiça. São Paulo: Companhia das Letras, 2011.

INSTITUTO NACIONAL DE ESTUDOS E PESQUISAS EDUCACIONAIS ANÍSIO TEIXEIRA. Sinopse Estatística da Educação Superior 2016. Brasília: INEP, 2017. Disponível em: 〈http://portal.inep.gov.br/web/guest/sinopses-estatisticas-da-educacao-superior >. Acesso em: 25 jun. 2018.

TOMELIN, Janes Fidélis. Perfil das instituições que ofertam EAD no Brasil. In. ABED. Censo EAD.BR: Relatório Analítico da Aprendizagem à Distância no Brasil. Curitiba: InterSaberes, 2017. Disponível em:

$<$ http://abed.org.br/censoead2016/Censo EAD 2016 portugues.pdf $>$. Acesso em: 25 jun. 2018. 